\title{
BMJ Open The impact of chronic kidney disease and cardiovascular comorbidity on mortality in a multiethnic population: a retrospective cohort study
}

\author{
Mark Jesky, ${ }^{1,2}$ Amanda Lambert, ${ }^{3}$ A C Felix Burden, ${ }^{4}$ Paul Cockwell ${ }^{1,2}$
}

To cite: Jesky M, Lambert A, Burden ACF, et al. The impact of chronic kidney disease and cardiovascular comorbidity on mortality in a multiethnic population: a retrospective cohort study. BMJ Open 2013;3:e003458. doi:10.1136/bmjopen-2013003458

- Prepublication history and additional material for this paper is available online. To view these files please visit the journal online (http://dx.doi.org/10.1136/ bmjopen-2013-003458).

Received 21 June 2013 Revised 4 September 2013 Accepted 23 October 2013

CrossMark

\footnotetext{
${ }^{1}$ Department of Renal Medicine, Queen Elizabeth Hospital Birmingham, Birmingham, UK ${ }^{2}$ Division of Infection and Immunity, University of Birmingham, Birmingham, UK

${ }^{3}$ Public Health Intelligence Birmingham City Council, Birmingham, UK

${ }^{4}$ Sandwell and West Birmingham Clinical Commissioning Group, Birmingham, UK
}

Correspondence to Mark Jesky; mark.jesky@uhb.nhs.uk

\section{ABSTRACT}

Objective: To assess the impact of chronic kidney disease (CKD) and cardiovascular comorbidity on mortality in a multiethnic primary care population.

Design: Retrospective cohort study.

Setting: Inner-city primary care trust in West Midlands, UK.

Participants: Individuals aged 40 years and older, of South Asian, black or white ethnicity, registered with a general practice and with their kidney function checked within the last 12 months ( $n=31254)$.

Outcome measure: All-cause mortality.

Results: Reduced estimated glomerular filtration rate, higher albuminuria, older age, white ethnicity (vs South Asian or black ethnicity) and increasing cardiovascular comorbidities were independent determinants of a higher mortality risk. In the multivariate model including comorbidities and kidney function, the HR for mortality for South Asians was 0.697 (95\% $\mathrm{Cl} 0.56$ to 0.868 , $\mathrm{p}=0.001)$ and for blacks it was $0.533(95 \% \mathrm{Cl} 0.403$ to $0.704, p<0.001$ ) compared to whites.

Conclusions: The HR for death is lower for South Asian and black individuals compared to white individuals. This is, in part, independent of age, gender, socioeconomic status, kidney function and comorbidities. Risk of death is higher in individuals with CKD and with a higher cumulative cardiovascular comorbidity.

\section{INTRODUCTION}

Chronic kidney disease (CKD) is a risk factor for increased mortality, ${ }^{1}$ with an increased risk of death associated with declining excretory renal function and albuminuria. ${ }^{2-4}$ CKD prevalence and the risk imparted by CKD may vary by ethnicity; for example, some studies indicate that CKD is more common in people of white ethnicity, ${ }^{5}$ but non-white ethnic groups have a faster progression to end-stage kidney disease. ${ }^{7} 8$ Paradoxically, when treated with chronic dialysis treatment, people of non-white ethnicity have a
Strengths and limitations of this study

- Sample size with inclusion of many practices.

- Ethnicity data self-reported and well recorded $(>80 \%)$.

- Individuals of white ethnicity relatively underrepresented.

lower mortality risk than people of white ethnicity. ${ }^{9}{ }^{10}$ An increased risk of death is also associated with other comorbidities, including hypertension, diabetes and cardiovascular (CV) disease. ${ }^{11-16}$

While previous studies have indicated survival differences between ethnic groups, ${ }^{8}$ 17-21 there has been limited reporting in these studies on the relative impact of comorbidities including kidney function on a population basis. This paucity of data reflects a shortfall in the availability of populationbased primary care databases linked to estimated glomerular filtration rate (eGFR) and albuminuria reporting and traceable to mortality. Furthermore, there is minimal comparative data on people of South Asian ethnicity; comparative studies usually report data on Chinese-Asians. ${ }^{5}$

In the UK, there has been a systematic improvement in chronic disease recognition through a primary care pay for performance system, the Quality and outcomes framework (QOF). ${ }^{22}{ }^{23}$ This system utilises chronic disease registers for the identification, monitoring and management of patients with known comorbidities; a component of this monitoring involves measuring and documenting renal function. These disease registers can be combined with laboratory results and linked with demographic and mortality data to better identify determinants of outcomes.

We have therefore utilised chronic disease registers to perform a retrospective cohort 
study of the relationship between CKD, CV comorbidity and mortality within a deprived, inner-city multiethnic population. Our study hypotheses were

1. There are differences in mortality between different ethnic groups.

2. These differences in mortality are explained by known risk factors including comorbidities, renal function, demographic and socioeconomic factors.

This study incorporated all stages of kidney function except stage 5 CKD (an eGFR below $15 \mathrm{~mL} / \mathrm{min}$ / $1.73 \mathrm{~m}^{2}$ ) in patients with known CV comorbidities and focused on three ethnic groups: South Asian (including individuals of Bangladeshi, Indian and Pakistani descent), black (individuals from, or who have ancestors from, Africa or the Caribbean) and white.

\section{METHODS}

\section{Ethics}

The data were fully anonymised and were available as a component of an ongoing clinical development programme. The responsible National Health Service (NHS) R\&D Consortium stated that this study did not require ethical submission to an NHS research ethics committee as it represented an evaluation of part of an ongoing primary care trust (PCT) programme. For PCT data extraction, the PCT professional executive committee and general practitioner (GP) locality leads provided approval for the programme, including evaluation and publication.

\section{Cohort identification}

The cohort was derived from Heart of Birmingham (Teaching) Primary Care Trust (HoB PCT), which had a registered population of 312070 (September 2008). The majority of the population $(62 \%)$ were non-white. ${ }^{24}$ Sixty-nine per cent of the population were below 40 years of age. Data were collected centrally, utilising software able to identify comorbidities through their classification on chronic disease registers (Enhanced Healthcare Services, Essex, UK). Complete sets of anonymised data were available for 63 of 73 general practices within HoB PCT, comprising a population of 285 221, and these were extracted from electronic downloads. Figure 1 illustrates the selection process for inclusion in the study.

The inclusion criteria comprised individuals aged 40 years and over who had kidney function testing performed within the previous 12 months as recommended by national guidelines. ${ }^{25}$ Data for the following variables were collected: age, gender, ethnicity, current smoking status, socioeconomic status (SES), eGFR and/or creatinine, urinary albumin : creatinine ratio (ACR) and vascular comorbidity (atrial fibrillation, CKD, diabetes mellitus, heart failure, hypertension, ischaemic heart disease and stroke) as defined by a relevant clinical (Read) code specified by the UK pay for performance (QOF) business rules. ${ }^{26}$ Ethnicity was self-reported, considered the 'gold standard' for classification. ${ }^{27}$
A standardised isotope dilution mass spectrometry (IDMS) MDRD eGFR ${ }^{28}$ was reported from one of three local biochemistry laboratories; however, eGFR reporting was not universally recorded on primary care systems in 2008 and if this was not available, the eGFR was calculated by utilising laboratory provided correction factors for the creatinine to generate IDMS-traceable MDRD eGFR. One general practice in the catchment area was excluded as IDMS-traceable creatinine was not available from a fourth laboratory that provided blood tests specifically for that catchment area.

SES was assessed using the Index of Multiple Deprivation $^{29}$; this utilises the postcode from an individual's address to identify the lower layer super output area (LSOA) where the individual resides. Each of the 32482 LSOAs in England are assigned a score and rank for the IMD 2007, with lower ranks corresponding to the most deprived areas. The IMD has been validated as superior to traditional deprivation indexes such as the Townsend score, ${ }^{30}$ due to its use of multiple domains reflective of socioeconomic deprivation. ${ }^{31}$ The IMD 2007 score incorporates seven areas of deprivation: income deprivation; employment deprivation; health deprivation and disability; education; skills and training deprivation; barriers to housing and services; living environment deprivation and crime. For the analyses presented, deprivation was divided into national quintiles, with the most deprived quintile as the reference population (ie, how mortality in less deprived quintiles compared to the most deprived quintile).

Mortality data were obtained from the Primary Care Mortality Database, ${ }^{32}$ a resource developed by The NHS Information Centre in partnership with the Office for National Statistics (ONS). Data obtained from ONS records are linked to the general practice where the individual was registered and therefore allow data to be extracted for specific general practices (ie, those within HoB PCT). Individuals included in this analysis were either still registered with an HoB PCT GP at the end of the follow-up period or had died while still registered at the practice. 9,907 (11.1\%) individuals who had left, and therefore were no longer registered with their practices, were excluded from the analysis. The follow-up period was 23 months from May 2008 until February 2011.

\section{Statistical analyses}

All analyses were performed using PASW statistics 18 for Windows (IBM, Chicago, Illinois, USA).

Measurements for kidney function were divided into categories; eGFR into six categories (15-29, 30-44, 45-59, $60-89,90-119$ and $\geq 120 \mathrm{~mL} / \mathrm{min}$ ) with the eGFR range between 90 and $119 \mathrm{~mL} / \mathrm{min}$ as the reference population. Individuals with an eGFR $<15 \mathrm{~mL} / \mathrm{min}$ were excluded from the analysis. ACR was divided into five categories ( $<1.1 \mathrm{mg} / \mathrm{mmol}$ 'optimal', 1.1-2.99 'high normal', 3-29.99 'high', 30-199.99 'very high' and $\geq 200$ 'nephrotic') in line with the KDIGO consensus conference. ${ }^{33}$ 


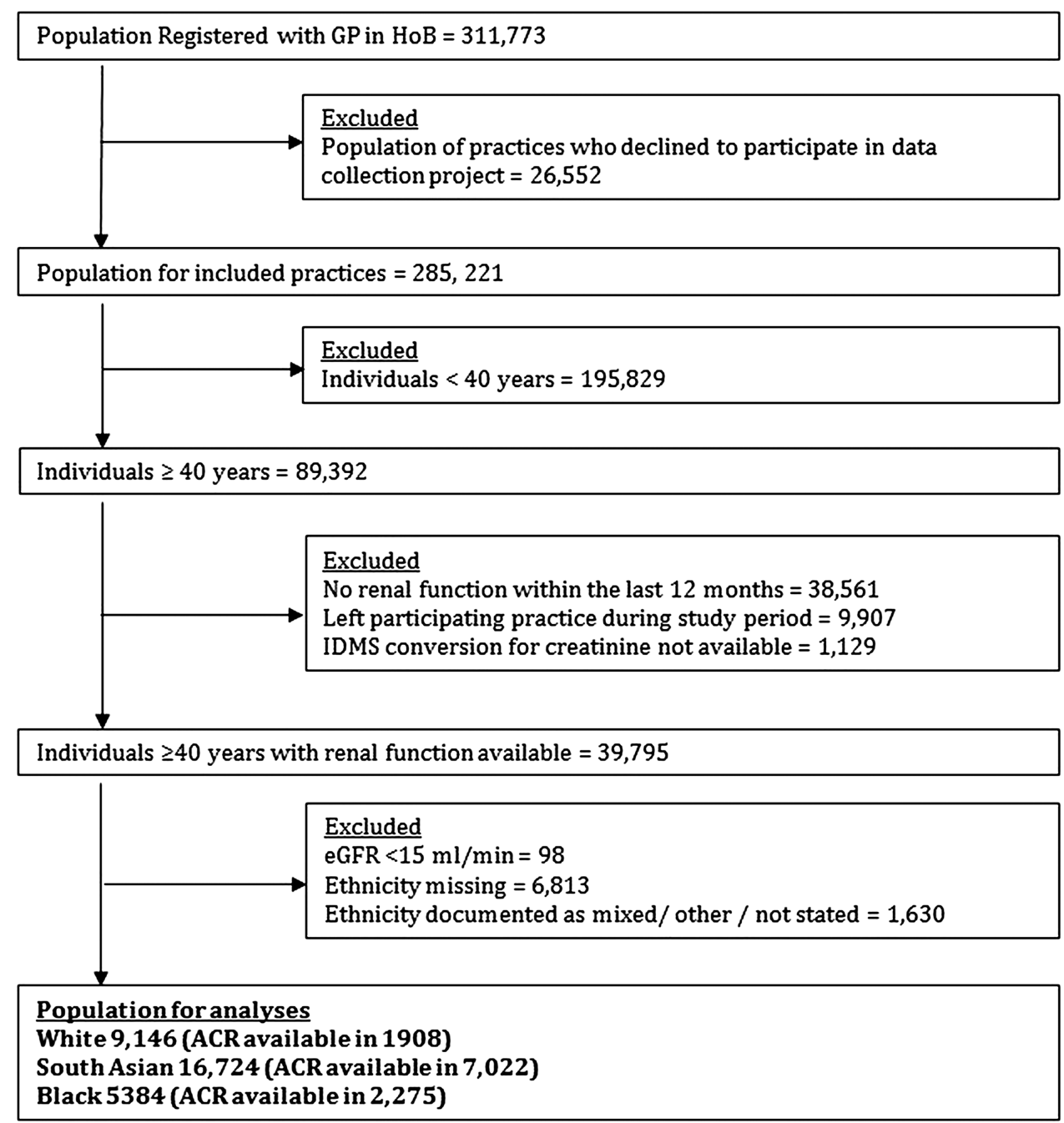

Figure 1 Flow diagram indicating selection process for inclusion in the analyses (ACR, albumin : creatinine ratio; eGFR, estimated glomerular filtration rate; IDMS, isotope dilution mass spectrometry; GP, general practitioner; HoB, Heart of Birmingham).

The relationship between age and mortality was not linear. Therefore, age was divided into six categories ( 50 years and under, 51-60, 61-70, 71-80, 81-90, greater than 90 years), with the youngest group serving as comparator.

Descriptive statistics are presented as mean with SD or median with IQR depending on distribution. Continuous variables were compared using analysis of variance (normal distribution) with post hoc Bonferroni analysis or Kruskal-Wallis (non-parametric distribution) tests. $\chi^{2}$ Tests were used to compare categorical variables.

Cox regression survival analysis was used to evaluate the association of ethnicity and mortality, both before and after adjusting for covariates. Data are presented using survival plots, HRs with $95 \%$ CI and p values. Both univariate (unadjusted) and multivariate (adjusted) regression analyses are presented. The proportionality hazard assumption, assessed using $\log (-\log$ (survival function)) plots, was met for all covariates.

The association between comorbidity, ethnicity and mortality was assessed by univariate analyses for all risk factors and then presented as three models. The choice of model variables was determined by the availability in the dataset of demographic and clinical risk factors consistent with those utilised by other investigators in previous work in similar populations, ${ }^{34} 35$ where the variable was available in our target population. Model 1 incorporates the number of identified vascular comorbidities (0-7), ethnicity, age, gender, smoking status and SES. Model 2 includes the eGFR level with removal of CKD from the comorbidity score (the possible scores are therefore 0-6) in order to avoid the association between declining renal function and the likelihood of being on the CKD register. Model 3 added ACR to the variables in model 2.

A complete case model was used in the analyses. All data were complete with the exception of ACR. Therefore, data were analysed for all individuals identified (unadjusted, models 1 and 2) and then repeated for individuals who had an ACR recorded (unadjusted and models 1-3). An 'enter' technique was used for the regression analysis. 


\section{RESULTS}

\section{Complete cohort}

At inception (May 2008), 31254 individuals fulfilled the inclusion criteria for analysis. People of South Asian ethnicity formed the largest ethnic group (16 724, 53.4\%), followed by people of white ethnicity $(9146,29.3 \%)$ and black ethnicity $(5384,17.2 \%)$. Baseline characteristics of the study population are shown in table 1 . The age distribution differed between groups with South Asians significantly younger than the other two ethnic groups. There was no significant difference in gender between the three ethnic groups. Smoking was least common in the South Asian group. The majority of all three ethnic groups resided in the most deprived quintile, with a higher proportion of people of South Asian and black ethnicity in this quintile than people of white ethnicity.

The number of vascular comorbidities was similar between groups, with 11-13\% of each ethnic group having three or more comorbidities. Prevalence of different vascular comorbidities varied between groups: the white group had a lower reported prevalence of diabetes but a higher prevalence of CKD, atrial fibrillation, heart failure and stroke.

Median eGFR (corrected for ethnicity as appropriate) was $80.2 \mathrm{~mL} / \mathrm{min}$ and was lowest in the white group $(74.9 \mathrm{~mL} / \mathrm{min}$ compared to $81.3 \mathrm{~mL} / \mathrm{min}$ for South Asian individuals and $85.5 \mathrm{~mL} / \mathrm{min}$ for those of black ethnicity; $\mathrm{p}<0.001) .21 .5 \%$ of white, $13.8 \%$ of South Asian and $11.5 \%$ of black individuals had an eGFR between 15 and $59 \mathrm{~mL} / \mathrm{min}$, consistent with stages 3-4 CKD.

At the end of the study period, a higher proportion of white individuals had died (7.4\%) compared to the two other ethnic groups (South Asian 3.2\%, black 4\%; $\mathrm{p}<0.001)$.

\section{Albumin creatinine ratio cohort}

An ACR cohort had been tested in 7022 (42\%), 2275 (24.9\%) and 1908 (20.9\%) South Asian, black and white individuals, respectively. Table 2 lists the baseline characteristics for this subgroup. The median ACR was $1.1 \mathrm{mg} /$ mmol and was highest in the South Asian group (1.2 compared to $1.0 \mathrm{mg} / \mathrm{mmol}$ for both white and black individuals; $p<0.001)$. There were similar trends to the whole cohort for age distribution, eGFR, smoking status and deprivation.

Those with an ACR tested were more likely to have a greater vascular comorbid burden (18-20\% having three or more comorbidities). A higher proportion of individuals of South Asian descent, male gender and with diabetes had their ACR tested.

In concordance to the whole group analyses, deaths in the ACR cohort were highest among white individuals $(7.8 \%)$ compared to the South Asian (3.6\%) and black individuals $(3.7 \% ; \mathrm{p}<0.001)$.

\section{Univariate analysis}

The univariate (unadjusted) analysis for the complete cohort (table 3a) demonstrated unadjusted HRs for death of 0.421 (95\% CI 0.376 to $0.471, \mathrm{p}<0.001)$ for people of South Asian ethnicity and 0.522 (95\% CI 0.447 to $0.609, \mathrm{p}<0.001$ ) for people of black ethnicity compared to people of white ethnicity. The mortality rate increased exponentially with age and a higher HR was observed for male gender, current smokers and total number of comorbidities. No difference in mortality was found between deprivation quintiles. Using an eGFR of 90-119 $\mathrm{mL} / \mathrm{min}$ as the reference, a J-shaped relationship was observed with a higher risk of death seen for higher and lower eGFR values. The HR for death increased progressively by stage of CKD with an eGFR $<90 \mathrm{~mL} / \mathrm{min}$.

The univariate analysis was repeated for those individuals who had their ACR reported (table 3b) with similar trends identified in the whole population analysis with the exception of no observed difference between individuals with an eGFR of $\geq 120$ compared to 90 $119 \mathrm{~mL} / \mathrm{min}$. A progressive increase in HR for death was seen with each increasing category for ACR.

\section{Multivariate analysis}

Following adjustment for covariates, the differences in ethnicity remained; people of South Asian and black ethnicities had a lower HR for death in all analyses.

Model 1 (complete cohort, incorporating the number of identified comorbidities, see online supplementary table I) analysed the complete cohort and showed an adjusted HR for death of 0.673 (95\% CI 0.595 to 0.761 , $\mathrm{p}<0.001)$ for people of South Asian ethnicity and 0.592 (95\% CI 0.504 to $0.696, \mathrm{p}<0.001$ ) for people of black ethnicity compared to people of white ethnicity. When the analysis was restricted to the cohort with ACR tests available, the HR for death was 0.757 (95\% CI 0.61 to 0.939 , $\mathrm{p}=0.011$ ) for people of South Asian ethnicity and 0.526 for people of black ethnicity (95\% CI 0.4 to 0.692 , $\mathrm{p}<0.001)$ compared to people of white ethnicity. For the complete cohort, mortality risk was lower in IMD quintiles 3 and 4 (compared to the most deprived quintile 5). No significant difference between IMD quintiles was identified in the ACR cohort. Increasing age (51 and over in the complete cohort, 61 and over in the ACR cohort), smoking status and male gender was significant in analyses for both cohorts. An increased HR for death was observed for two or more comorbidities, with the HR increasing as the number of comorbidities increased.

Kidney function (eGFR) was incorporated into model 2 (with the removal of CKD from the comorbidity score, see online supplementary table I), and in the complete cohort HR for people of South Asian ethnicity was 0.678 (95\% CI 0.6 to $0.767, \mathrm{p}<0.001$ ) and for people of black ethnicity it was $0.614(95 \%$ CI 0.522 to $0.722, \mathrm{p}<0.001)$ compared to people of white ethnicity. Similarly, when the analysis was restricted to the cohort of patients with ACR tests available, people of South Asian and black ethnicity had a lower proportion of deaths compared to people of white ethnicity with HRs of 0.789 (95\% CI 0.635 to $0.98, \mathrm{p}=0.032)$ and 0.575 (95\% CI 0.435 to 
Table 1 Baseline characteristics by ethnicity: complete cohort

\begin{tabular}{|c|c|c|c|c|c|}
\hline & All & White & South Asian & Black & p Value \\
\hline \multicolumn{6}{|l|}{ Number } \\
\hline n (\%) & $31254(100)$ & $9146(29.3)$ & $16724(53.4)$ & $5384(17.2)$ & \\
\hline \multicolumn{6}{|l|}{ Age } \\
\hline Median (lower, upper quartile) & $59.0(50.0,71.0)$ & $65.0(55.0,75.0)$ & $56.0(49.0,68.0)$ & $61.0(48.0,73.0)$ & $<0.001$ \\
\hline 50 and under (\%) & $8421(26.9)$ & $1515(16.6)$ & $5124(30.6)$ & $1782(33.1)$ & $<0.001$ \\
\hline $51-60(\%)$ & 8017 (25.7) & $1948(21.3)$ & $5170(30.9)$ & 899 (16.7) & \\
\hline $61-70(\%)$ & $6650(21.3)$ & 2459 (26.9) & 3206 (19.2) & 985 (18.3) & \\
\hline $71-80(\%)$ & $6006(19.2)$ & $2109(23.1)$ & $2568(15.4)$ & $1329(24.7)$ & \\
\hline $81-90(\%)$ & $1974(6.3)$ & $1008(11.0)$ & $604(3.6)$ & $362(6.7)$ & \\
\hline$>90(\%)$ & $186(0.6)$ & 107 (1.2) & $52(0.3)$ & $27(0.5)$ & \\
\hline \multicolumn{6}{|l|}{ Gender } \\
\hline Female (\%) & $15248(48.8)$ & 4384 (47.9) & 8184 (48.9) & 2680 (49.8) & 0.085 \\
\hline \multicolumn{6}{|l|}{ Smoking } \\
\hline $\mathrm{n}(\%)$ & $5150(16.5)$ & $2285(25.0)$ & $1812(10.8)$ & $1053(19.6)$ & $<0.001$ \\
\hline \multicolumn{6}{|l|}{ IMD rank } \\
\hline Quintile 1 (least deprived) (\%) & $152(0.5)$ & $59(0.6)$ & $92(0.6)$ & $1(0.0)$ & $<0.001$ \\
\hline Quintile $2(\%)$ & $316(1.0)$ & $132(1.4)$ & $173(1.0)$ & $11(0.2)$ & \\
\hline Quintile 3 (\%) & $3348(10.7)$ & $1860(20.3)$ & $1255(7.5)$ & $233(4.3)$ & \\
\hline Quintile 4 (\%) & $5144(16.5)$ & $2243(24.5)$ & $2238(13.4)$ & $663(12.3)$ & \\
\hline Quintile 5 (most deprived) (\%) & 22294 (71.3) & $4852(53.1)$ & 12966 (77.5) & $4476(83.1)$ & \\
\hline \multicolumn{6}{|c|}{ AF } \\
\hline n (\%) & $807(2.6)$ & $515(5.6)$ & $212(1.3)$ & $80(1.5)$ & $<0.001$ \\
\hline \multicolumn{6}{|l|}{ CKD } \\
\hline n (\%) & 3648 (11.7) & $1318(14.4)$ & $1691(10.1)$ & 639 (11.9) & $<0.001$ \\
\hline \multicolumn{6}{|l|}{ Diabetes } \\
\hline n (\%) & $9931(31.8)$ & $1771(19.4)$ & $6415(38.4)$ & $1745(32.4)$ & $<0.001$ \\
\hline \multicolumn{6}{|l|}{ Heart failure } \\
\hline n (\%) & $822(2.6)$ & $308(3.4)$ & $385(2.3)$ & $129(2.4)$ & $<0.001$ \\
\hline \multicolumn{6}{|l|}{ Hypertension } \\
\hline n (\%) & $16505(52.8)$ & $5181(56.6)$ & 8063 (48.2) & $3261(60.6)$ & $<0.001$ \\
\hline \multicolumn{6}{|l|}{ IHD } \\
\hline n (\%) & $4226(13.5)$ & $1417(15.5)$ & $2386(14.3)$ & $423(7.9)$ & $<0.001$ \\
\hline \multicolumn{6}{|l|}{ Stroke } \\
\hline n (\%) & $1476(4.7)$ & $570(6.2)$ & $673(4.0)$ & $233(4.4)$ & $<0.001$ \\
\hline \multicolumn{6}{|l|}{ Comorbidities } \\
\hline Median (lower, upper quartile) & $1.0(0.0,2.0)$ & $1.0(0.0,2.0)$ & $1.0(0.0,2.0)$ & $1.0(0.0,2.0)$ & 0.075 \\
\hline $0(\%)$ & $9879(31.6)$ & $2829(30.9)$ & $5459(32.6)$ & $1591(29.6)$ & $<0.001$ \\
\hline $1 \%)$ & 10707 (34.3) & $3253(35.6)$ & $5524(33)$ & 1930 (35.8) & \\
\hline $2(\%)$ & $6845(21.9)$ & $1898(20.8)$ & $3694(22.1)$ & $1253(23.3)$ & \\
\hline $3(\%)$ & 2667 (8.5) & $785(8.6)$ & $1451(8.7)$ & $431(8)$ & \\
\hline $4(\%)$ & $828(2.6)$ & $254(2.8)$ & $447(2.7)$ & $127(2.4)$ & \\
\hline $5(\%)$ & $268(0.9)$ & $103(1.1)$ & $124(0.7)$ & $41(0.8)$ & \\
\hline $6(\%)$ & $55(0.2)$ & $23(0.3)$ & $23(0.1)$ & $9(0.2)$ & \\
\hline $7(\%)$ & $5(<0.1)$ & $1(<0.1)$ & $2(<0.1)$ & $2(<0.1)$ & \\
\hline \multicolumn{6}{|l|}{ Creatinine $(\mu \mathrm{mol} / \mathrm{L})$} \\
\hline Mean (SD) & $87.0(25.8)$ & $88.2(24.7)$ & $84.6(25.4)$ & $92.3(28)$ & $<0.001$ \\
\hline \multicolumn{6}{|l|}{ eGFR (mL/min) } \\
\hline Median (lower, upper quartile) & $80.2(66.7,94.3)$ & $74.9(62.3,88.8)$ & $81.3(68.1,95.3)$ & $85.5(72.3,100.1)$ & $<0.001$ \\
\hline$>120(\%)$ & $1473(4.7)$ & $264(2.9)$ & $802(4.8)$ & $407(7.6)$ & $<0.001$ \\
\hline $90-120(\%)$ & 8523 (27.3) & $1842(20.1)$ & 4841 (28.9) & 1840 (34.2) & \\
\hline $60-89(\%)$ & $16373(52.4)$ & $5077(55.5)$ & $8776(52.5)$ & $2520(46.8)$ & \\
\hline $45-59(\%)$ & $3447(11.0)$ & 1389 (15.2) & $1627(9.7)$ & 431 (8.0) & \\
\hline $30-44(\%)$ & $1134(3.6)$ & $466(5.1)$ & $517(3.1)$ & $151(2.8)$ & \\
\hline $15-29(\%)$ & $304(1.0)$ & 108 (1.2) & $161(1.0)$ & $35(0.7)$ & \\
\hline \multicolumn{6}{|l|}{ Died } \\
\hline n (\%) & $1435(4.6)$ & $681(7.4)$ & 541 (3.2) & $213(4.0)$ & $<0.001$ \\
\hline
\end{tabular}

$\mathrm{ACR}$, albumin : creatinine ratio; $\mathrm{AF}$, atrial fibrillation; $\mathrm{CKD}$, chronic kidney disease; eGFR, estimated glomerular filtration rate; IHD, ischaemic heart disease; IMD, Index of Multiple Deprivation. 
Table 2 Baseline characteristics by ethnicity: ACR-tested cohort

\begin{tabular}{|c|c|c|c|c|c|}
\hline & All & White & South Asian & Black & p Value \\
\hline \multicolumn{6}{|l|}{ Number } \\
\hline \multicolumn{6}{|l|}{ Age (years) } \\
\hline Median (lower, upper quartile) & $59.0(50.0,71.0)$ & $65.0(55.0,75.0)$ & $57.0(50.0,68.0)$ & $65.0(49.0,74.0)$ & $<0.001$ \\
\hline 50 and under (\%) & $1900(25.9)$ & $304(15.9)$ & $1961(27.9)$ & $635(27.9)$ & $<0.001$ \\
\hline $51-60(\%)$ & $3024(27.0)$ & $413(21.6)$ & 2239 (31.9) & $372(16.4)$ & \\
\hline $61-70(\%)$ & $2370(21.2)$ & $496(26.0)$ & $1423(20.3)$ & $451(19.8)$ & \\
\hline $71-80(\%)$ & $2251(20.1)$ & $456(23.9)$ & $1152(16.2)$ & $643(28.3)$ & \\
\hline $81-90(\%)$ & $611(5.5)$ & $222(11.6)$ & $226(3.2)$ & $163(7.2)$ & \\
\hline$>90(\%)$ & $49(0.4)$ & $17(0.9)$ & $21(0.3)$ & $11(0.5)$ & \\
\hline \multicolumn{6}{|l|}{ Gender } \\
\hline Female (\%) & $4348(38.8)$ & $682(35.7)$ & 2754 (39.2) & $912(40.1)$ & 0.008 \\
\hline \multicolumn{6}{|l|}{ Smoking } \\
\hline $\mathrm{n}(\%)$ & $1869(16.7)$ & $518(27.1)$ & $872(12.4)$ & $479(21.1)$ & $<0.001$ \\
\hline \multicolumn{6}{|l|}{ IMD rank } \\
\hline Quintile 1 (least deprived) (\%) & $30(0.3)$ & $4(0.2)$ & $25(0.4)$ & $1(0.0)$ & $<0.001$ \\
\hline Quintile 2 (\%) & $84(0.7)$ & $19(1.0)$ & $60(0.9)$ & $5(0.2)$ & \\
\hline Quintile $3(\%)$ & $712(6.4)$ & $233(12.2)$ & $540(5.7)$ & 78 (3.4) & \\
\hline Quintile 4 (\%) & $1458(13.0)$ & $339(17.8)$ & $876(12.5)$ & $243(10.7)$ & \\
\hline Quintile 5 (most deprived) (\%) & $8921(79.6)$ & $1313(68.8)$ & $5660(80.6)$ & 1948 (85.6) & \\
\hline \multicolumn{6}{|l|}{$\mathrm{AF}$} \\
\hline $\mathrm{n}(\%)$ & $233(2.1)$ & $113(5.9)$ & $91(1.3)$ & $29(1.3)$ & $<0.001$ \\
\hline \multicolumn{6}{|l|}{ CKD } \\
\hline $\mathrm{n}(\%)$ & $1637(14.6)$ & $356(18.7)$ & $921(13.1)$ & $360(15.8)$ & $<0.001$ \\
\hline \multicolumn{6}{|l|}{ Diabetes } \\
\hline $\mathrm{n}(\%)$ & $6828(60.9)$ & $990(51.9)$ & 4505 (62.4) & $1333(58.6)$ & $<0.001$ \\
\hline \multicolumn{6}{|l|}{ Heart failure } \\
\hline $\mathrm{n}(\%)$ & $310(2.8)$ & $74(3.9)$ & $175(2.5)$ & $61(2.7)$ & 0.005 \\
\hline \multicolumn{6}{|l|}{ Hypertension } \\
\hline $\mathrm{n}(\%)$ & $6189(55.2)$ & $1092(57.2)$ & 3679 (52.4) & $1418(62.3)$ & $<0.001$ \\
\hline \multicolumn{6}{|l|}{ IHD } \\
\hline n (\%) & $1556(13.9)$ & $281(14.7)$ & $1071(15.3)$ & $201(8.8)$ & $<0.001$ \\
\hline \multicolumn{6}{|l|}{ Stroke } \\
\hline $\mathrm{n}(\%)$ & $480(4.3)$ & $97(5.1)$ & $283(4.0)$ & $100(4.4)$ & 0.126 \\
\hline \multicolumn{6}{|l|}{ Comorbidities } \\
\hline Median (lower, upper quartile) & $1.0(1.0,2.0)$ & $2.0(1.0,2.0)$ & $1.0(1.0,2.0)$ & $2.0(1.0,2.0)$ & 0.818 \\
\hline $0(\%)$ & 2510 (22.4) & $472(24.7)$ & $1514(21.6)$ & $524(23.0)$ & $<0.001$ \\
\hline $1(\%)$ & $3139(28.0)$ & $466(24.4)$ & $2103(29.9)$ & $870(25.1)$ & \\
\hline $2(\%)$ & 3438 (30.7) & $574(30.1)$ & $2093(29.8)$ & 771 (33.9) & \\
\hline $3(\%)$ & 1481 (13.2) & $261(13.7)$ & $928(13.2)$ & $292(12.8)$ & \\
\hline $4(\%)$ & $448(4.0)$ & 79 (4.1) & $284(4.0)$ & $85(3.7)$ & \\
\hline $5(\%)$ & $154(1.4)$ & $46(2.4)$ & $83(1.2)$ & $25(1.1)$ & \\
\hline $6(\%)$ & $32(0.3)$ & $10(0.5)$ & $15(0.2)$ & $7(0.3)$ & \\
\hline 7 (\%) & $3(<0.1)$ & $0(<0.1)$ & $2(<0.1)$ & $1(<0.1)$ & \\
\hline \multicolumn{6}{|l|}{ Creatinine $(\mu \mathrm{mol} / \mathrm{L})$} \\
\hline Mean (SD) & $89.1(27.6)$ & $91.8(26.2)$ & $86.2(26.8)$ & $95.8(29.6)$ & $<0.001$ \\
\hline \multicolumn{6}{|l|}{ eGFR (mL/min) } \\
\hline Median (lower, upper quartile) & $81.1(66.3,95.9)$ & $74.3(59.7,89.8)$ & $82(67.4,89.8)$ & $84.2(70.0,98.9)$ & $<0.001$ \\
\hline$>120(\%)$ & $611(5.5)$ & $67(3.5)$ & $380(5.4)$ & $164(7.2)$ & $<0.001$ \\
\hline $90-120$ (\%) & 3234 (28.9) & $404(21.2)$ & 2091 (29.8) & 739 (32.5) & \\
\hline $60-89(\%)$ & $5451(48.6)$ & 953 (49.9) & $3453(49.2)$ & 1045 (45.9) & \\
\hline $45-59(\%)$ & $1300(11.6)$ & $323(16.9)$ & $750(10.7)$ & $227(10.0)$ & \\
\hline $30-44(\%)$ & $487(4.3)$ & $131(6.9)$ & $274(3.9)$ & $82(3.6)$ & \\
\hline $15-29(\%)$ & $122(1.1)$ & $30(1.6)$ & $74(1.1)$ & $18(0.8)$ & \\
\hline \multicolumn{6}{|l|}{ ACR $(\mathrm{mg} / \mathrm{mmol})$} \\
\hline Median (lower, upper quartile) & $1.1(0.4,3.4)$ & $1.0(1.4,2.8)$ & $1.2(0.5,3.8)$ & $1.0(0.3,2.9)$ & $<0.001$ \\
\hline Optimal $(<1.1)(\%)$ & $5641(50.3)$ & $1026(53.8)$ & $3400(48.4)$ & $1214(53.4)$ & $<0.001$ \\
\hline High normal (1.1-2.99) (\%) & 2485 (22.2) & 426 (22.3) & $1560(22.2)$ & 499 (21.9) & \\
\hline
\end{tabular}


Table 2 Continued

\begin{tabular}{|c|c|c|c|c|c|}
\hline & All & White & South Asian & Black & p Value \\
\hline High (3.0-29.99) (\%) & 2594 (23.2) & $402(21.1)$ & $1717(24.4)$ & $475(20.9)$ & \\
\hline Very high (30-200) (\%) & $413(3.7)$ & $49(2.6)$ & $287(4.1)$ & $77(3.4)$ & \\
\hline Nephrotic (>200) (\%) & $73(0.7)$ & $5(0.3)$ & $58(0.8)$ & $10(0.4)$ & \\
\hline \multicolumn{6}{|l|}{ Died } \\
\hline n (\%) & $484(4.3)$ & $149(7.8)$ & $250(3.6)$ & $85(3.7)$ & $<0.001$ \\
\hline
\end{tabular}

$0.759, \mathrm{p}<0.001)$, respectively. In the complete cohort, mortality risk was lower in the IMD quintile 4. More than two comorbidities were associated with an increasing $\mathrm{HR}$ and an increased $\mathrm{HR}$ of death compared to the reference eGFR range $(90-119 \mathrm{~mL} / \mathrm{min})$ was seen with an eGFR $\geq 120$ and $\geq 45 \mathrm{~mL} / \mathrm{min}$. An eGFR of $60-$ $89 \mathrm{~mL} / \mathrm{min}$ was associated with a lower HR. In the analysis of those with ACR tested, an eGFR $<60 \mathrm{~mL} / \mathrm{min}$ was associated with progressively higher HR by CKD stage.

In model 3 (all vascular comorbidities except CKD and the addition of eGFR and ACR, table 4), the HR for death for people of South Asian ethnicity was 0.697 (95\% CI 0.56 to $0.868, \mathrm{p}=0.001$ ) and for people of black ethnicity it was $0.533(95 \%$ CI 0.403 to $0.704, \mathrm{p}<0.001)$ compared to people of white ethnicity (figure 2). Older age, male gender, being a current smoker and increasing comorbidity (two or more) were associated with an increased HR of death (figure 3). An ACR of 'high' or greater (ie, $\geq 3.0 \mathrm{mg} / \mathrm{mmol}$ ) and an eGFR $<45 \mathrm{~mL} / \mathrm{min}$ was also associated with an increased HR for death. No significant differences in HRs were observed between deprivation quintiles.

\section{DISCUSSION}

This study utilised routinely available clinical and laboratory data, including kidney function assessed by eGFR and ACR, from a large primary care population. We included in the analysis detailed SES and, importantly, studied three ethnic groups, South Asian, black and white. Prior to this research, there has been uncertainty about the impact of ethnicity and SES on clinical outcomes in people with significant comorbidities including CKD. The comprehensive nature of the dataset coupled with the ability to utilise the Primary Care Mortality Database has allowed us to assess the relative impact of these factors on survival.

We found that previous associations between lower eGFR and higher ACR and increased mortality applied to this population. Furthermore, these associations remained significant when adjusted for ethnicity, age, gender, CV risk factors and SES. These results add weight to the risk stratification benefit of measuring ACR has in high-risk groups.

A strong cumulative impact of comorbidity on CKD and ethnicity was shown. Whereas traditional comorbidity scores such as the Charlson Comorbidity Index $^{36}$ are difficult to calculate accurately in a large primary care setting, our study demonstrates that a simple cumulative score provides prognostic information. Individual comorbidities were present in varying frequencies within different ethnic groups, a finding consistent with that found in other ethnically diverse populations. ${ }^{37}$ While individual comorbidities were associated with different mortality risks, we found that the cumulative effect of comorbidities conveyed the greatest prognostic implication. A similar approach, but also including non-CV risk factors, has recently been described. ${ }^{38}$ Our study suggests that routinely collected clinical data concerning cumulative comorbidity may be utilised to quantify risk; however, further work would be required to validate this as a tool for use in clinical care.

SES was measured by the IMD 2007 score, a cumulative deprivation index score incorporating seven areas of deprivation which has been validated as superior to other deprivation scores. ${ }^{31}$ One notable finding is that we did not demonstrate any association between mortality when corrected for all other factors including comorbidity and ethnicity. This is not consistent with several other studies, which have shown that there is an independent relationship between SES and mortality across disease states and ethnic groups within the UK. ${ }^{39-42}$ This relationship varies by population group studied ${ }^{43}$ and there have been limited studies investigating health disparities in similar inner-city populations. While we studied a healthcare system that is free at the point of care, limiting possible health access issues, the majority of individuals were from the most deprived national quintile and our study may therefore underestimate the influence of the complete spectrum of SES on mortality. To attempt to correct for this, we reran the analyses dividing the cohort into equal quintiles. All analyses continued to indicate the effect of ethnicity and the importance of CV comorbidity and renal function. The univariate analysis (see online supplementary table II) and the most comprehensive multivariate analysis (model 3, see online supplementary table III) did not show any differences between the most and least deprived quintiles.

One of the seven areas included in the IMD is health deprivation, raising the possibility of an inbuilt relationship between deprivation and health even before 
Table 3 Cox proportional hazard regression analysis: univariate (unadjusted) analyses

\begin{tabular}{|c|c|c|c|c|}
\hline & \multicolumn{2}{|l|}{ Complete cohort (3a) } & \multicolumn{2}{|l|}{ ACR tested cohort (3b) } \\
\hline & $\mathrm{HR}(95 \% \mathrm{Cl})$ & p Value & HR (95\% Cl) & p Value \\
\hline \multicolumn{5}{|l|}{ Ethnicity } \\
\hline White & 1 & $\left(<0.001^{\star}\right)$ & 1 & $\left(<0.001^{*}\right)$ \\
\hline South Asian & 0.421 (0.376 to 0.471$)$ & $<0.001$ & 0.444 (0.362 to 0.545$)$ & $<0.001$ \\
\hline Black & $0.522(0.447$ to 0.609$)$ & $<0.001$ & 0.467 (0.357 to 0.611$)$ & $<0.001$ \\
\hline \multicolumn{5}{|l|}{ Age (years) } \\
\hline 50 and under & 1 & $\left(<0.001^{\star}\right)$ & 1 & $\left(<0.001^{*}\right)$ \\
\hline $51-60$ & 2.127 (1.553 to 2.914$)$ & $<0.001$ & 1.757 (1.057 to 2.921$)$ & 0.03 \\
\hline $61-70$ & 5.429 (4.078 to 7.228$)$ & $<0.001$ & 4.646 (2.926 to 7.345$)$ & $<0.001$ \\
\hline $71-80$ & 12.971 (9.887 to 17.016$)$ & $<0.001$ & $11.363(7.376$ to 17.505$)$ & $<0.001$ \\
\hline $81-90$ & $32.86(29.952$ to 43.275$)$ & $<0.001$ & 24.725 (15.769 to 38.767$)$ & $<0.001$ \\
\hline$>90$ & 90.904 (65.097 to 126.943$)$ & $<0.001$ & 82.731 (46.684 to 146.612$)$ & $<0.001$ \\
\hline \multicolumn{5}{|l|}{ Gender } \\
\hline Female as reference & 1.375 (1.238 to 1.529$)$ & $<0.001$ & 1.401 (1.155 to 1.699$)$ & 0.001 \\
\hline \multicolumn{5}{|l|}{ Smoker } \\
\hline Non-smoker as reference & 1.154 (1.009 to 1.317$)$ & 0.036 & 1.259 (1.006 to 1.574$)$ & 0.044 \\
\hline \multicolumn{5}{|l|}{ IMD rank } \\
\hline Quintile 1 (least deprived) & 0.860 (0.385 to 1.919$)$ & 0.713 & $<0.001\left(<0.001 \longrightarrow>10^{\wedge} 5\right)$ & 0.939 \\
\hline Quintile 2 & $0.822(0.465$ to 1.453$)$ & 0.501 & $<0.001\left(<0.001 \rightarrow>10^{\wedge} 5\right)$ & 0.897 \\
\hline Quintile 3 & $1.002(0.846$ to 1.186$)$ & 0.983 & 1.151 (0.818 to 1.619$)$ & 0.419 \\
\hline Quintile 4 & $0.925(0.800$ to 1.070$)$ & 0.297 & 0.774 (0.577 to 1.039$)$ & 0.088 \\
\hline Quintile 5 (most deprived) & 1 & $\left(0.802^{*}\right)$ & 1 & $\left(0.42^{*}\right)$ \\
\hline $\mathrm{AF}$ & 5.588 (4.757 to 6.565$)$ & $<0.001$ & 6.123 (4.568 to 8.207 ) & $<0.001$ \\
\hline CKD & 3.442 (3.074 to 3.854$)$ & $<0.001$ & 3.498 (2.904 to 4.213 ) & $<0.001$ \\
\hline Diabetes & 1.346 (1.209 to 1.498$)$ & $<0.001$ & 1.939 (1.577 to 2.385$)$ & $<0.001$ \\
\hline Heart failure & $7.622(6.595$ to 8.804$)$ & $<0.001$ & 7.279 (5.681 to 9.327 ) & $<0.001$ \\
\hline Hypertension & 2.079 (1.857 to 2.325$)$ & $<0.001$ & 2.05 (1.681 to 2.499$)$ & $<0.001$ \\
\hline IHD & 2.796 (2.495 to 3.132$)$ & $<0.001$ & 3.136 (2.592 to 3.795$)$ & $<0.001$ \\
\hline Stroke & 3.654 (3.154 to 4.233$)$ & $<0.001$ & 3.709 (2.855 to 4.817$)$ & $<0.001$ \\
\hline \multicolumn{5}{|l|}{ Comorbidities } \\
\hline 0 & 1 & $\left(<0.001^{*}\right)$ & 1 & $\left(<0.001^{\star}\right)$ \\
\hline 1 & 1.775 (1.487 to 2.118$)$ & $<0.001$ & 1.630 (1.094 to 2.430$)$ & 0.016 \\
\hline 2 & 2.930 (2.458 to 3.493$)$ & $<0.001$ & 2.917 (2.023 to 4.205$)$ & $<0.001$ \\
\hline 3 & $5.486(4.550$ to 6.615$)$ & $<0.001$ & 5.580 (3.837 to 8.113$)$ & $<0.001$ \\
\hline 4 & 9.584 (7.691 to 11.942$)$ & $<0.001$ & 9.855 (6.511 to 14.917$)$ & $<0.001$ \\
\hline 5 & 17.591 (13.490 to 22.939$)$ & $<0.001$ & 21.091 (13.479 to 33.001$)$ & $<0.001$ \\
\hline 6 & 28.391 (18.411 to 43.782 ) & $<0.001$ & 33.673 (17.519 to 64.722$)$ & $<0.001$ \\
\hline 7 & 11.873 (1.664 to 84.728$)$ & 0.014 & 29.402 (4.031 to 214.462$)$ & 0.001 \\
\hline \multicolumn{5}{|l|}{ eGFR (mL/min) } \\
\hline$>120$ & $1.492(1.110$ to 2.007$)$ & 0.008 & $1.072(0.603$ to 1.903$)$ & 0.813 \\
\hline $90-120$ & 1 & $\left(<0.001^{\star}\right)$ & 1 & $\left(<0.001^{*}\right)$ \\
\hline $60-89$ & $1.360(1.162$ to 1.591$)$ & $<0.001$ & 1.504 (1.138 to 1.987$)$ & 0.04 \\
\hline $45-59$ & 3.849 (3.239 to 4.573$)$ & $<0.001$ & 4.255 (3.155 to 5.737 ) & $<0.001$ \\
\hline $30-44$ & 6.590 (5.401 to 8.041$)$ & $<0.001$ & 7.715 (5.564 to 10.699$)$ & $<0.001$ \\
\hline $15-29$ & 14.465 (11.341 to 18.450$)$ & $<0.001$ & 15.054 (9.942 to 22.796$)$ & $<0.001$ \\
\hline \multicolumn{5}{|l|}{ ACR (mg/mmol) } \\
\hline Optimal $(<1.1)$ & & & 1 & $\left(<0.001^{*}\right)$ \\
\hline High normal (1.1-2.99) & & & 1.363 (1.038 to 1.788$)$ & 0.026 \\
\hline High (3.0-29.99) & & & 2.967 (2.381 to 3.697 ) & $<0.001$ \\
\hline Very high $(30-200)$ & & & 6.253 (4.493 to 14.005$)$ & $<0.001$ \\
\hline Nephrotic (>200) & & & $7.932(4.493$ to 14.005$)$ & $<0.001$ \\
\hline
\end{tabular}

analyses are undertaken. The possible implication of this was investigated by Adams and White ${ }^{44}$ who analysed data having removed the health domain from IMD 2004 and found that its removal had little practical effect. This suggests that the presence of the health domain is unlikely to influence our result. 
Table 4 Cox proportional hazard regression analysis: multivariate (adjusted) analyses (model 3)

\begin{tabular}{|c|c|c|}
\hline & \multicolumn{2}{|l|}{ ACR tested cohort } \\
\hline & HR (95\% Cl) & p Value \\
\hline \multicolumn{3}{|l|}{ Ethnicity } \\
\hline South Asian & 0.697 (0.56 to 0.868$)$ & 0.001 \\
\hline Black & $0.533(0.403$ to 0.704$)$ & $<0.001$ \\
\hline \multicolumn{3}{|l|}{ Age (years) } \\
\hline $61-70$ & 3.521 (2.17 to 5.712$)$ & $<0.001$ \\
\hline $71-80$ & 7.381 (4.61 to 11.818$)$ & $<0.001$ \\
\hline $81-90$ & 15.721 (9.534 to 25.922$)$ & $<0.001$ \\
\hline$>90$ & 51.641 (27.889 to 95.621$)$ & $<0.001$ \\
\hline \multicolumn{3}{|l|}{ Gender } \\
\hline Quintile 1 (least deprived) & $<0.001\left(<0.001\right.$ to $\left.>10^{\wedge} 5\right)$ & 0.952 \\
\hline Quintile 2 & $<0.001\left(<0.001\right.$ to $\left.>10^{\wedge} 5\right)$ & 0.913 \\
\hline Quintile 3 & $0.978(0.68$ to 1.387$)$ & 0.902 \\
\hline Quintile 4 & 0.788 (0.585 to 1.062$)$ & 0.118 \\
\hline Quintile 5 (most deprived) & 1 & $\left(0.65^{\star}\right)$ \\
\hline \multicolumn{3}{|l|}{ Comorbidities } \\
\hline 0 & 1 & $\left(<0.001^{\star}\right)$ \\
\hline 1 & 1.371 (0.932 to 2.016$)$ & 0.109 \\
\hline 2 & 1.486 (1.019 to 2.166$)$ & 0.039 \\
\hline 3 & $2.29(1.53$ to 3.428$)$ & $<0.001$ \\
\hline 4 & 3.153 (2.002 to 4.964$)$ & $<0.001$ \\
\hline 15-29 & 2.073 (1.315 to 3.268$)$ & 0.002 \\
\hline \multicolumn{3}{|l|}{$\mathrm{ACR}(\mathrm{mg} / \mathrm{mmol})$} \\
\hline Optimal $(<1.1)$ & 1 & $\left(<0.001^{\star}\right)$ \\
\hline High normal (1.1-2.99) & 1.032 (0.784 to 1.359$)$ & 0.821 \\
\hline High (3.0-29.99) & 1.837 (1.464 to 2.305$)$ & $<0.001$ \\
\hline Very high (30-200) & 2.956 (2.132 to 4.099$)$ & $<0.001$ \\
\hline Nephrotic $(>200)$ & 3.838 (2.108 to 6.985$)$ & $<0.001$ \\
\hline
\end{tabular}

We found that the risk of death was lower for people of South Asian and black ethnicity compared to people of white ethnicity, and this remained in all analyses (adjusted and unadjusted) performed. Previous studies comparing the outcomes of different ethnic groups have been limited in their generalisability. They have either looked at disease-specific mortality ${ }^{8182021}$ or have been based in populations that do not have access to freecomprehensive healthcare. The finding that differences in mortality risk between ethnic groups is independent of age, gender, SES, kidney function and comorbidities requires further work. Variables such as health promotion targeted at specific groups, differences in medication usage or factors related to genetic diversity may offer potential explanations for this variation. ${ }^{45} 46$

A major strength in this study is the sample size, which included 62 practices of varying list size and a number of practitioners. Ethnicity was documented in over $80 \%$ of the population studied; this is much higher than is normally found in primary care records. ${ }^{47}$ Self-reporting is considered the 'gold standard' method of assessing ethnicity, ${ }^{27}$ taking into account an individual's culture 


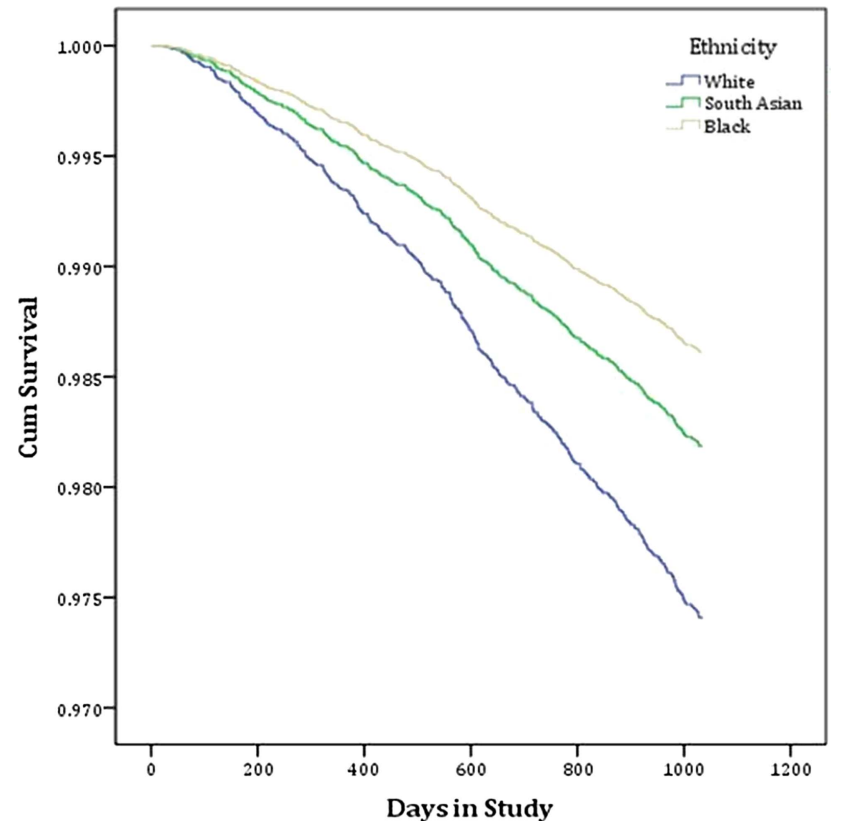

Figure 2 Cox regression survival plot indicating cumulative survival between ethnicities in model 3 (comorbidities, estimated glomerular filtration rate and albumin : creatinine ratio). Table below survival plot demonstrates the number of individuals who remained in follow-up at each time point.

and self-identity. Renal function was described in terms of eGFR and ACR, the latter assuming increased prominence in the stratification of CV risk.

Our analyses have used data from primary care coding and recording systems, which formed part of the

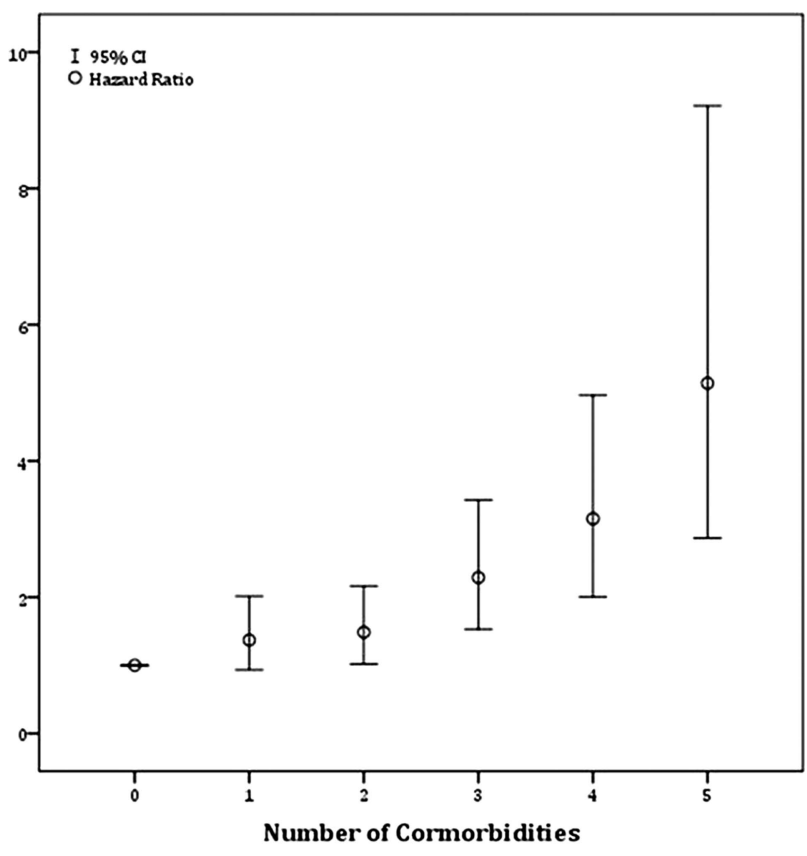

HR not illustrated for 6 comorbidities; HR 10.54 (95\% CI 2.52 - 44.084)

Figure 3 HR for death by number of comorbidities. Multivariate (adjusted) analysis: model 3. electronic downloads. These downloads indicate who is on a specific CV risk register and therefore may not classify people correctly. There is a relative paucity of published literature regarding the correct identification of people onto the correct risk registers. ${ }^{23}{ }^{48-50}$ Surrogate measures of accuracy of the data include previous studies looking at gaming for QOF points (falsely classifying people with conditions they do not have, thereby increasing revenue) or exception reporting (excluding individuals who have not had the appropriate monitoring completed) suggesting that both these are rare. ${ }^{235152}$

When comparing the breakdown of the population studied in these analyses with the source population, it is important to highlight two key differences. First, there is a relative underrepresentation of individuals of white ethnicity, consistent with previous research. ${ }^{53}$ This is most marked in those who had their ACR measured; a higher number of men and individuals with diabetes or of South Asian ethnicity had their ACR measured. Comparing the whole cohort to those who had their ACR reported showed similar trends for mortality in respect of age, eGFR, smoking status and SES, suggesting a generalisability of results. Second, one criterion for inclusion was the recording of renal function within the previous 12 months. This is likely to have resulted in an overrepresentation of comorbidity as people with $\mathrm{CV}$ conditions would be more likely to have their renal function checked. A further consideration is that the accuracy and applicability of creatinine-based eGFR equations, such as the formula used in this analysis, in non-white ethnic groups is a subject of ongoing research. ${ }^{54-56}$ Cystatin-based equations may be more accurate,${ }^{57}$ but are not routinely measured in clinical practice.

In summary, we have shown that the determinants of mortality were multifactorial in a high-risk population and that ethnicity should be considered as a nontraditional risk factor for mortality; the HR for death was lower for South Asian and black individuals compared to white individuals, which was, in part, independent of age, gender, SES, renal function and comorbidities. Furthermore, a simple cumulative comorbidity system may have prognostic utility. Renal function (eGFR and ACR) provides additional information and gender, while age and smoking status remain significant risk factors for mortality.

Contributors MJ participated in the study design, data analysis and preparation of the manuscript. AL participated in the study design, data acquisition and analysis and review of the manuscript. ACFB participated in the study design, data acquisition and review of the manuscript. PC participated in the study design, data analysis, preparation and review of the manuscript.

Funding This research received no specific grant from any funding agency in the public, commercial or not-for-profit sectors.

Competing interests MJ has received funding from the JABBS Foundation. ACFB has advised and received honoraria from Enhanced Healthcare Services Ltd. 
Ethics approval The data were fully anonymised and were available as a component of an ongoing clinical development programme. The responsible NHS R\&D Consortium stated that this study did not require ethical submission to an NHS research ethics committee as it represented an evaluation of part of an ongoing primary care trust (PCT) programme. For PCT data extraction, the PCT professional executive committee and GP locality leads provided approval for the programme, including evaluation and publication.

Provenance and peer review Not commissioned; externally peer reviewed.

Data sharing statement No additional data are available.

Open Access This is an Open Access article distributed in accordance with the Creative Commons Attribution Non Commercial (CC BY-NC 3.0) license, which permits others to distribute, remix, adapt, build upon this work noncommercially, and license their derivative works on different terms, provided the original work is properly cited and the use is non-commercial. See: http:// creativecommons.org/licenses/by-nc/3.0/

\section{REFERENCES}

1. Go AS, Chertow GM, Fan D, et al. Chronic kidney disease and the risks of death, cardiovascular events, and hospitalization. $N$ Engl $J$ Med 2004;351:1296-305.

2. Matsushita K, van der Velde M, Astor BC, et al. Association of estimated glomerular filtration rate and albuminuria with all-cause and cardiovascular mortality in general population cohorts: a collaborative meta-analysis. Lancet 2010;375:2073-81.

3. Astor BC, Matsushita K, Gansevoort RT, et al. Lower estimated glomerular filtration rate and higher albuminuria are associated with mortality and end-stage renal disease. A collaborative meta-analysis of kidney disease population cohorts. Kidney Int 2011;79:1331-40.

4. Gansevoort RT, Matsushita K, van der Velde M, et al. Lower estimated GFR and higher albuminuria are associated with adverse kidney outcomes. A collaborative meta-analysis of general and high-risk population cohorts. Kidney Int 2011;80:93-104.

5. Zhang QL, Rothenbacher D. Prevalence of chronic kidney disease in population-based studies: systematic review. BMC Public Health 2008;8:117

6. Coresh J, Selvin E, Stevens LA, et al. Prevalence of chronic kidney disease in the United States. JAMA 2007;298:2038-47.

7. Peralta CA, Katz R, Deboer I, et al. Racial and ethnic differences in kidney function decline among persons without chronic kidney disease. J Am Soc Nephrol 2011;22:1327-34.

8. Barbour SJ, Er L, Djurdjev O, et al. Differences in progression of CKD and mortality amongst Caucasian, Oriental Asian and South Asian CKD patients. Nephrol Dial Transplant 2010;25:3663-72.

9. Choi Al, Rodriguez RA, Bacchetti $P$, et al. White/black racial differences in risk of end-stage renal disease and death. Am J Med 2009;122:672-8.

10. Crews DC, Sozio SM, Liu Y, et al. Inflammation and the paradox of racial differences in dialysis survival. J Am Soc Nephrol 2011;22:2279-86.

11. Hallan SI, Matsushita K, Sang Y, et al. Age and association of kidney measures with mortality and end-stage renal disease. JAMA 2012;308:2349-60.

12. Herzog CA, Asinger RW, Berger AK, et al. Cardiovascular disease in chronic kidney disease. A clinical update from Kidney Disease: Improving Global Outcomes (KDIGO). Kidney Int 2011;80:572-86.

13. Mahmoodi BK, Matsushita K, Woodward M, et al. Associations of kidney disease measures with mortality and end-stage renal disease in individuals with and without hypertension: a meta-analysis. Lancet 2012;380:1649-61.

14. Benjamin EJ, Wolf PA, D'Agostino RB, et al. Impact of atrial fibrillation on the risk of death: the Framingham Heart Study. Circulation 1998;98:946-52.

15. Ford ES. Trends in mortality from all causes and cardiovascular disease among hypertensive and nonhypertensive adults in the United States. Circulation 2011;123:1737-44.

16. Afkarian M, Sachs MC, Kestenbaum B, et al. Kidney disease and increased mortality risk in type 2 diabetes. J Am Soc Nephrol 2013;24:302-8.

17. Bahrami $\mathrm{H}$, Kronmal R, Bluemke DA, et al. Differences in the incidence of congestive heart failure by ethnicity: the multi-ethnic study of atherosclerosis. Arch Intern Med 2008;168:2138-45.
18. Balarajan R. Ethnic differences in mortality from ischaemic heart disease and cerebrovascular disease in England and Wales. BMJ 1991;302:560-4.

19. Cappuccio FP. Ethnicity and cardiovascular risk: variations in people of African ancestry and South Asian origin. $J$ Hum Hypertens 1997:11:571-6.

20. Khan NA, Wang $\mathrm{H}$, Anand $\mathrm{S}$, et al. Ethnicity and sex affect diabetes incidence and outcomes. Diabetes Care 2011;34:96-101.

21. Chaturvedi N, Jarrett J, Morrish N, et al. Differences in mortality and morbidity in African Caribbean and European people with non-insulin dependent diabetes mellitus: results of 20 year follow up of a London cohort of a multinational study. BMJ 1996;313:848-52.

22. Shekelle P. New contract for general practitioners. $B M J$ 2003;326:457-8.

23. Calvert M, Shankar A, McManus RJ, et al. Effect of the quality and outcomes framework on diabetes care in the United Kingdom: retrospective cohort study. BMJ 2009;338:b1870.

24. PEEG, Current Estimates, Population Estimates by Ethnic Group Mid-2002-2008 for Primary Care Organisations (experimental). Secondary PEEG, Current Estimates, Population Estimates by Ethnic Group Mid-2002-2008 for Primary Care Organisations (experimental) 02/03/2009. 2008. http://www.ons.gov.uk/ons/ taxonomy/index.html?nscl=Population+Estimates+by+Ethnic+Group

25. National Institute for Health and Clinical Excellence: CG73: Chronic Kidney Disease. Secondary National Institute for Health and Clinical Excellence: CG73: Chronic Kidney Disease 2008. http://www.nice. org.uk/CG73

26. Centre HaSCl. Quality and Outcomes Framework. Secondary Quality and Outcomes Framework. http://www.hscic.gov.uk/qof

27. Saunders CL, Abel GA, El Turabi A, et al. Accuracy of routinely recorded ethnic group information compared with self-reported ethnicity: evidence from the English Cancer Patient Experience survey. BMJ Open 2013;3:pii: e002882.

28. Levey AS, Bosch JP, Lewis JB, et al. A more accurate method to estimate glomerular filtration rate from serum creatinine: a new prediction equation. Modification of Diet in Renal Disease Study Group. Ann Intern Med 1999;130:461-70.

29. Index of Multiple Deprivation (IMD) 2007. Secondary Index of Multiple Deprivation (IMD) 2007 26/1/2013 2007. http://data.gov.uk/ dataset/index of multiple deprivation imd 2007

30. Townsend P, Phillimore P, Beattie A. Health and deprivation: inequality and the north. London: Croom Helm, 1988.

31. Jordan $\mathrm{H}$, Roderick P, Martin D. The Index of Multiple Deprivation 2000 and accessibility effects on health. J Epidemiol Community Health 2004:58:250-7.

32. Centre HSCl. Primary Care Mortality Database. Secondary Primary Care Mortality Database. http://www.hscic.gov.uk/pcmdatabase

33. Levey AS, de Jong PE, Coresh $\mathrm{J}$, et al. The definition, classification, and prognosis of chronic kidney disease: a KDIGO Controversies Conference report. Kidney Int 2011;80:17-28.

34. Abbasi A, Peelen LM, Corpeleijn E, et al. Prediction models for risk of developing type 2 diabetes: systematic literature search and independent external validation study. BMJ 2012;345:e5900.

35. Smith S, Waterall J, Burden AC. An evaluation of the performance of the NHS Health Check programme in identifying people at high risk of developing type 2 diabetes. BMJ Open 2013;3:pii: e002219.

36. Charlson ME, Pompei P, Ales KL, et al. A new method of classifying prognostic comorbidity in longitudinal studies: development and validation. J Chronic Dis 1987:40:373-83.

37. Khunti K, Morris DH, Weston CL, et al. Joint prevalence of diabetes, impaired glucose regulation, cardiovascular disease risk and chronic kidney disease in South Asians and White Europeans. PLOS ONE 2013;8:e55580.

38. Carey IM, Shah SM, Harris T, et al. A new simple primary care morbidity score predicted mortality and better explains between practice variations than the Charlson index. $J$ Clin Epidemiol 2013:66:436-44.

39. Johnson-Lawrence V, Kaplan G, Galea S. Socioeconomic mobility in adulthood and cardiovascular disease mortality. Ann Epidemiol 2013:23:167-71.

40. Lazzarino Al, Hamer M, Stamatakis E, et al. The combined association of psychological distress and socioeconomic status with all-cause mortality: a national cohort study. JAMA Intern Med 2013;173:22-7.

41. Jackson CA, Jones NR, Walker JJ, et al. Area-based socioeconomic status, type 2 diabetes and cardiovascular mortality in Scotland. Diabetologia 2012;55:2938-45

42. Gallo V, Mackenbach JP, Ezzati M, et al. Social inequalities and mortality in Europe-results from a large multi-national cohort. PLOS ONE 2012;7:e39013. 
43. Levene LS, Bankart J, Khunti K, et al. Association of primary care characteristics with variations in mortality rates in England: an observational study. PLoS ONE 2012;7:e47800.

44. Adams J, White M. Removing the health domain from the Index of Multiple Deprivation 2004-effect on measured inequalities in census measure of health. J Public Health (Oxf) 2006;28:379-83.

45. Conley J, Tonelli M, Quan H, et al. Association between GFR, proteinuria, and adverse outcomes among white, Chinese, and South Asian individuals in Canada. Am J Kidney Dis 2012;59:390-9.

46. Buckalew VM Jr, Freedman BI. Reappraisal of the impact of race on survival in patients on dialysis. Am J Kidney Dis 2010;55:1102-10.

47. Raleigh VS. Collection of data on ethnic origin in England. BMJ 2008;337:a1107.

48. Lambert AM, Burden AC, Chambers J, et al. Cardiovascular screening for men at high risk in Heart of Birmingham Teaching Primary Care Trust: the 'Deadly Trio' programme. J Public Health (Oxf) 2012;34:73-82

49. Humphreys J, Harvey G, Coleiro M, et al. A collaborative project to improve identification and management of patients with chronic kidney disease in a primary care setting in Greater Manchester. BMJ Qual Saf 2012;21:700-8.

50. Martin D, Wright JA. Disease prevalence in the English population: a comparison of primary care registers and prevalence models. Soc Sci Med 2009;68:266-74.
51. Doran T, Fullwood C, Reeves D, et al. Exclusion of patients from pay-for-performance targets by English physicians. $N$ Engl J Med 2008;359:274-84.

52. Campbell S, Hannon K, Lester H. Exception reporting in the Quality and Outcomes Framework: views of practice staff-a qualitative study. Br J Gen Pract 2011;61:183-9.

53. de Lusignan S, Nitsch D, Belsey J, et al. Disparities in testing for renal function in UK primary care: cross-sectional study. Fam Pract 2012;28:638-46.

54. Delanaye $\mathrm{P}$, Cavalier E, Mariat C, et al. Estimating glomerular filtration rate in Asian subjects: where do we stand? Kidney Int 2011:80:439-40.

55. Delanaye $\mathrm{P}$, Mariat $\mathrm{C}$, Maillard N, et al. Are the creatininebased equations accurate to estimate glomerular filtration rate in African American populations? Clin J Am Soc Nephrol 2011;6:906-12.

56. Matsushita K, Mahmoodi BK, Woodward M, et al. Comparison of risk prediction using the CKD-EPI equation and the MDRD study equation for estimated glomerular filtration rate. JAMA 2012;307:1941-51.

57. Teo $\mathrm{BW}, \mathrm{Xu} \mathrm{H}$, Wang $\mathrm{D}$, et al. Estimating glomerular filtration rates by use of both cystatin $C$ and standardized serum creatinine avoids ethnicity coefficients in Asian patients with chronic kidney disease. Clin Chem 2012;58:450-7. 